\title{
Penulisan Karya Ilmiah Melalui Perkuliahan Seminar Pendidikan Matematika Berbantuan E-Learning dan Media Sosial
}

\author{
Eyus Sudihartinih ${ }^{1}$, Habibi Ratu Perwira Negara ${ }^{2}$, Mimi Nur Hafizah ${ }^{3}$ \\ ${ }^{1}$ Universitas Pendidikan Indonesia, Jawa Barat, Indonesia, Jl. Dr. Setiabudhi No 229, Bandung \\ ${ }^{2}$ UIN Mataram, Nusa Tenggara Barat, Indonesia, Jl. Pendidikan No.35, Dasan Agung Baru, Mataram \\ ${ }^{3}$ Univeristas Negeri Jakarta, Jl. Pemuda No. 10 Rawamangun, Jakarta Timur. DKI Jakarta \\ eyuss84@upi.edu
}

\begin{abstract}
Students must have the ability to write scientific papers because this is a competency that must be possessed. Assistance in writing scientific papers is important to be given to students so that the purpose of this study is to describe the process of assisting scientific writing in Mathematics Education Seminar lectures assisted by elearning and social media. This research is holistic type case study. Content analysis procedures for qualitative data are collected to carry out interpretive investigations. Participants consisted of one class seventh semester students in the Mathematics Education Department at a university in West Java, Indonesia. The research instrument was a researcher, an open questionnaire, and an observation sheet. Based on the results of the research, it is known that the assistance in writing scientific papers can be carried out well by students through lectures on Mathematics Education Seminar assisted by e-learning and social media.
\end{abstract}

Keywords: e-learning, social media, scientific papers, qualitative research

\begin{abstract}
Abstrak
Mahasiswa harus memiliki kemampuan untuk menulis karya ilmiah karena ini adalah kompetensi yang harus dimiliki. Pendampingan penulisan karya ilmiah menjadi penting untuk diberikan kepada mahasiswa, sehingga tujuan dari penelitian ini adalah untuk menggambarkan proses pendampingan penulisan karya ilmiah dalam perkuliahan Seminar Pendidikan Matematika berbantuan e-learning dan media sosial. Penelitian ini adalah studi kasus tipe holistic. Prosedur analisis konten untuk data kualitatif dikumpulkan untuk melakukan penyelidikan interpretatif. Partisipan terdiri dari satu kelas mahasiswa semester VII di Departemen Pendidikan Matematika di salah satu universitas di Jawa Barat, Indonesia. Instrumen penelitian ini adalah peneliti, angket terbuka dan lembar observasi. Berdasarkan hasil penelitian diketahui bahwa pendampingan penulisan karya ilmiah dapat dilakukan dengan baik oleh mahasiswa melalui perkuliahan Seminar Pendidikan Matematika berbantuan e-learning dan media sosial. Selain itu, mahasiswa juga memberikan respons positif terhadap perkuliahan sehingga perkuliahan yang dibantu oleh e-learning dan media sosial dapat dilanjutkan dalam perkuliahan berikutnya dan diujikan pada penelitian lainnya.
\end{abstract}

Kata kunci: e-learning, sosial media, karya ilmiah, penelitian kualitatif

Copyright (c) 2022 Eyus Sudihartinih, Habibi Ratu Perwira Negara, Mimi Nur Hafizah

$\triangle$ Corresponding author: Eyus Sudihartinih

Email Address: eyuss84@upi.edu (J1. Dr. Setiabudhi No 229, Bandung)

Received 21 October 2021, Accepted 12 January 2022, Published 26 January 2022

\section{PENDAHULUAN}

Karya ilmiah adalah hal yang tidak asing bagi mahasiswa karena berbagai tugas seperti observasi, menganalisis, mengkritisi, dan tugas akhirnya adalah pembuatan karya ilmiah (Kurniadi, 2017). Penulisan karya ilmiah berperan sangat penting dan merupakan bagian dari tuntutan formal akademik (Peraturan Rektor UPI, 2018). Penulisan karya ilmiah memerlukan jembatan konseptual dari yang sudah diketahui, struktur kognitif untuk mendapatkan informasi, menjelaskannya sebagai presentasi untuk diinterpretasi terhadap hal-hal baru (Nasution, 2016). Menulis karya ilmiah adalah hal yang menyenangkan dan mudah untuk yang terbiasa tetapi sangat susah untuk yang belum pernah sehingga perlu proses membiasakan menulis dan berani memulainya (Hanum, 2009). Oleh karena itu 
Penulisan Karya Ilmiah Melalui Perkuliahan Seminar Pendidikan Matematika Berbantuan E-Learning dan Media Sosial, Eyus Sudihartinih, Habibi Ratu Perwira Negara, Mimi Nur Hafizah

dosen hendaknya dapat memfasilitasi mahasiswa agar mampu menulis karya ilmiah.

Untuk menghasilkan karya ilmiah yang baik dibutuhkan keterampilan teknik menulis yang memadai. Salah satu cara melatih kemampuan tersebut adalah melalui perkuliahan Seminar Pendidikan Matematika karena dalam mata kuliah tersebut produknya adalah makalah atau artikel karya ilmiah. Mata Kuliah Seminar Pendidikan Matematika akan memfasilitasi mahasiswa di Departemen Pendidikan Matematika untuk memahami dan mengkaji berbagai hal terkait teknik penyusunan dan penyajian karya ilmiah.

Pada era revolusi 4.0, penggunaan teknologi digital dalam pembelajaran tidak lagi terelakkan. Media yang dapat digunakan dalam perkuliahan di antaranya adalah e-learning dan media sosial. Elearning seringkali merupakan cara yang lebih efektif dan efisien karena belajar sesuai kebutuhannya, interaktif, dan dapat di mana saja (Bielawski \& Metcalf, 2003). Perkuliahan dengan e-learning mencakup konten (yaitu sebagai informasi) dan metode pengajaran (yaitu sebagai teknik) yang membantu orang mempelajari konten sehingga dapat mencapai tujuan pembelajaran (Clark \& Mayer, 2008). Dosen harus mampu menggunakan e-learning tidak bergantung pada admin dari e-learning agar kendala yang dihadapi oleh dosen dan mahasiswa dalam penggunaan e-learning dapat langsung diatasi oleh dosen tersebut (Saputra \& Pasundan, 2017). Oleh karena itu e-learning dalam penelitian ini langsung dikelola oleh dosen pengampu yaitu penulis sendiri.

E-learning adalah pengajaran yang disampaikan melalui komputer atau internet dengan fiturfitur berikut (Clark \& Mayer, 2008): (1) memberikan konten yang relevan dengan tujuan pembelajaran, (2) gunakan metode yang dapat membantu pembelajaran, (3) gunakan media seperti kata-kata dan gambar untuk menyampaikan informasi, (4) dapat dipimpin oleh instruktur, dan (5) membangun pengetahuan dan keterampilan baru yang terkait dengan tujuan pembelajaran.

Standardisasi menjadi faktor penentu keberhasilan yang harus mengikuti prinsip-prinsip yang harus ada dalam e-learning, berikut standarisasi dalam e-learning (Ehlers \& Pawlowski, 2006). 1) Transparansi: dapat meningkatkan transparansi proses dan sistem. Ini berarti bahwa semua pemangku kepentingan harus memiliki akses ke informasi yang terstruktur dengan jelas dan akurat. 2) Keterbukaan: dikembangkan dalam proses konsensus. Dalam proses ini, semua pemangku kepentingan harus dilibatkan, seperti pengembang, guru, perancang, dan yang paling penting yaitu pelajar. 3) Kemampuan beradaptasi: dapat disesuaikan dengan persyaratan nasional, regional, lokal, atau organisasi. 4) Ekstensibilitas: terbuka untuk ekstensi ketika persyaratan atau pengembangan baru terjadi. Ini berarti bahwa basisnya bisa stabil untuk jangka waktu yang lebih lama, hanya ekstensi yang perlu diintegrasikan.

Selain teknologi e-learning, pemanfaatan media sosial dalam pembelajaran juga kian marak. Tingginya tingkat pemakaian telepon pintar (smartphone) saat ini memicu hadirnya tren literasi digital yaitu kemampuan untuk memahami informasi berbasis perangkat digital. Fenomena maraknya generasi milenial mengakses media sosial dapat menjadi pertimbangan untuk memanfaatkan media sosial dalam pembelajaran (Assidik, 2018). 
Berdasarkan uraian tersebut tujuan penelitian ini adalah untuk menggambarkan proses pendampingan penulisan karya ilmiah dalam perkuliahan Seminar Pendidikan Matematika berbantuan e-learning dan media sosial.

\section{METODE}

Penelitian ini adalah studi kasus tipe holistic yaitu untuk mendeskripsikan barbagai temuan lapangan (Yin, 2009). Prosedur analisis konten untuk data kualitatif dikumpulkan untuk melakukan penyelidikan interpretatif. Partisipan penelitian ini adalah satu kelas yang terdiri dari tiga orang mahasiswa perempuan semester VII yang sedang mengikuti pembelajaran Seminar Pendidikan Matematika pada semester ganjil tahun ajaran 2019/2020, pada salah satu universitas di Jawa Barat, Indonesia. Pemilihan partisipan ini secara purposive sampling. Instrumen penelitian ini adalah peneliti untuk menganalisis semua temuan, angket terbuka untuk menjaring respons partisipan, dan lembar observasi untuk mengamati kegiatan partisipan. Adapun pertanyaan yang diberikan pada angket terbuka ada pada Tabel 1 dan Tabel 2. Selanjutnya data dianalisis dan diinterpretasikan. Prosedur analisis konten untuk data kualitatif dikumpulkan untuk melakukan penyelidikan interpretatif.

Adapun langkah penelitian yaitu dimulai dengan analisis silabus, persiapan bahan ajar, dan mengisi konten e-learning. Meskipun terdapat e-learning, tatap muka perkuliahan dilakukan setiap minggu pada jadwal dan tempat yang telah ditentukan. E-learning dan sosial media (penelitian ini digunakan WatshApp) hanya sebagai transfer bahan ajar yang berupa file, link jurnal, link buku, dan video. Mahasiswa harus enroll sendiri dengan password dari dosen untuk dapat login ke e-learning sehingga hanya partisipan yang dapat masuk. Pada e-learning tersebut terdapat 16 pertemuan, tiap pertemuan berisi bahan ajar yang berbeda-beda disertai dengan slot pengumpulan tugas. WhatsApp ini digunakan agar komunikasi dan informasi dapat cepat sampai pada mahasiswa sehingga perkuliahan berjalan lancar. Pada akhir perkuliahan penulis memberikan angket terbuka melalui Google Forms.

\section{HASIL DAN DISKUSI}

Perkuliahan ini menggunakan media e-learning SPADA yang telah disediakan dari universitas. Berikut contoh bahan ajar pertama yang ditunjukkan pada Gambar 1.

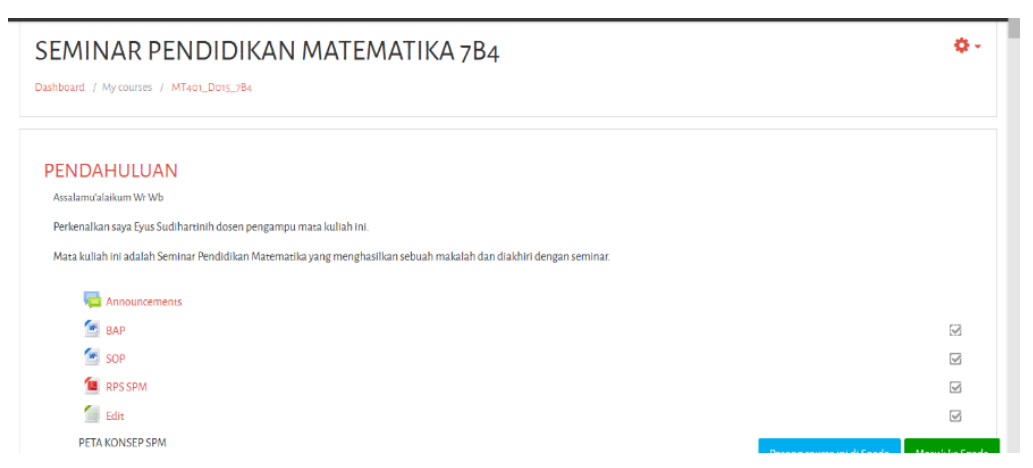

Gambar 1. Konten E-Learning Pertemuan Pertama 
Penulisan Karya Ilmiah Melalui Perkuliahan Seminar Pendidikan Matematika Berbantuan E-Learning dan Media Sosial, Eyus Sudihartinih, Habibi Ratu Perwira Negara, Mimi Nur Hafizah

E-learning pada pertemuan pertama dosen melampirkan berita acara perkuliahan (BAP), standar operasional prosedur (SOP) perkuliahan, rencana pembelajaran semester (RPS), dan peta konsep mata kuliah sehingga pada tatap muka perkuliahan ke-1 dosen menjelaskan secara singkat hal tersebut. Pada tatap muka pertemuan ke-1 juga dosen menjelaskan tujuan perkuliahan, media yang digunakan, aturan perkuliahan, dan cara mencari artikel jurnal. Selanjutnya mahasiswa diberi tugas mencari dan membaca 10 artikel yang dipilih dari Google Scholar dan Researchgate. Artikel dipilih secara bebas dan dituliskan ringkasannya pada gambar 2 .

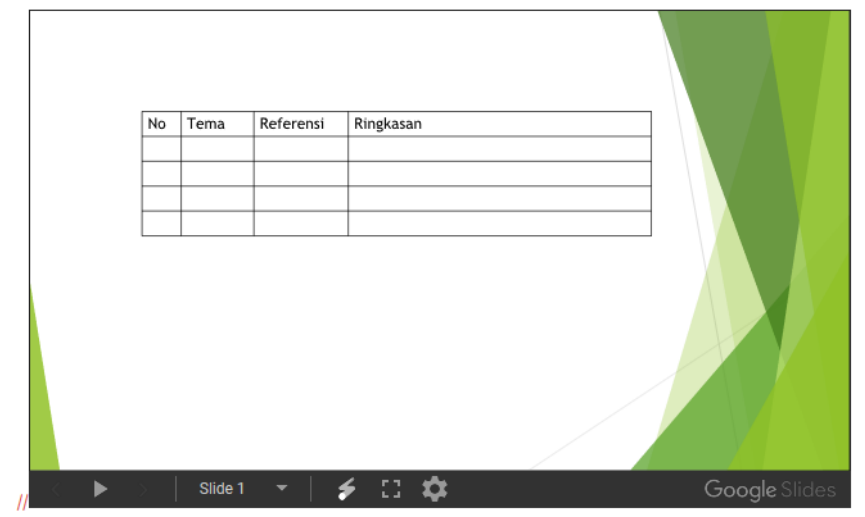

Gambar 2. Tabel Ringkasan Artikel

Tujuan dibuat tabel dalam gambar 2 adalah agar memudahkan mahasiswa saat menulis referensi pada artikel. Pertemuan ke-2 semua mahasiswa diminta presentasi artikel yang telah dibaca dan ditulis secara berurutan. Pada pertemuan ke-3 sampai dengan ke-7 mahasiswa ditugasi mencari dan membaca 15 artikel yang temanya telah dipilih mahasiswa sendiri untuk menjadi fokus artikel yang ditulis, serta dipresentasikan secara bergilir dalam setiap pertemuan. Tugas-tugas tersebut diunggah dalam e-learning setiap pekannya. Pertemuan ke-7, dosen melampirkan video yang berisi tentang cara penulisan artikel. Contoh bahan ajar pertemuan ke-7 ada pada gambar 3.

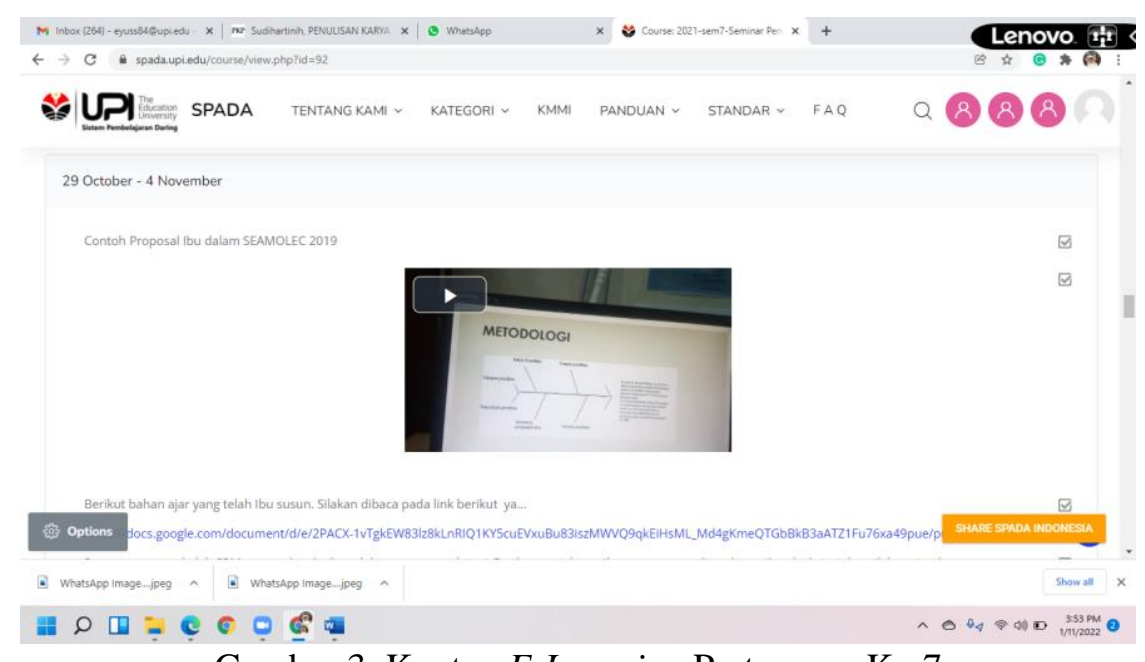

Gambar 3. Konten E-Learning Pertemuan Ke-7 
Selain video, dosen juga melampirkan modul cara penulisan artikel sehingga mahasiswa dapat memahami cara penulisan artikel. Modul tersebut berisi tentang rangkuman dari pelatihan penulisan artikel dalam berbagai kegiatan yang penulis ikuti.

Pertemuan ke-8 mahasiswa mengumpulkan hasil ringkasan artikel yang telah dibaca lengkap dengan referensinya yang nantinya ini menjadi pendahuluan dalam artikel. Tugas tersebut dosen cek kesamaannya menggunakan aplikasi Turnitin.

Konten e-learning pada pertemuan ke-9 sampai dengan ke-15 adalah slot tugas di setiap pertemuan dan file-file tentang metode penelitian dan cara penulisan karya ilmiah dari para professor yang diperoleh saat pelatihan penulisan karya ilmiah tahun 2014, tahun 2016, tahun 2017, tahun 2018, dan tahun 2019. Contoh konten tersebut ada pada gambar 4.

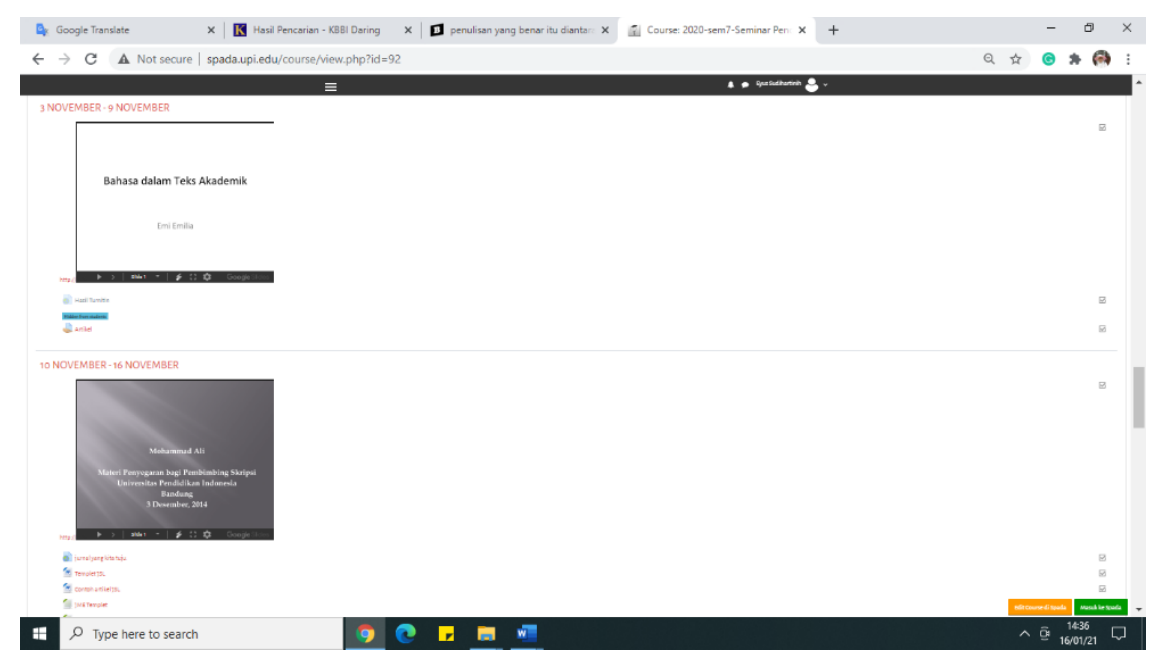

Gambar 4. Contoh file-file tentang metode penelitian dan cara penulisan

Selain itu dosen juga melampirkan link video tentang karya ilmiah dari web. Pada pertemuan ke-9 sampai ke-16 mahasiswa diminta membuat artikel yang akan dikirim ke jurnal yang dipilih mahasiswa sehingga pertemuan ke-9 mahasiswa diminta membuat instrumen penelitian. Dilanjutkan dengan pengambilan dan pengolahan data di luar pertemuan. Pada pertemuan ke-10 mahasiswa dilatih cara menggunakan aplikasi Mendeley untuk referensi dan mulai menulis artikel sesuai templete pada jurnal yang mahasiswa inginkan. Pada pertemuan ke-11 sampai ke-14 bimbingan penulisan artikel mulai dari pendahuluan, metode, hasil dan pembahasan, serta kesimpulan. Pada pertemuan ke-15 mahasiswa dilatih menggunakan aplikasi Grammarly dan aplikasi QuillBot. Dengan demikian urutan penulisan artikel adalah menulis pendahuluan dan kajian teori, menentukan metode penelitian, menyusun instrumen, mengambil data, olah data, pembahasan dan diskusi, serta ditutup dengan kesimpulan. Jika artikel berbahasa Inggris, maka artikel diterjemahkan dengan bantuan buku sumber matematika berbahasa Inggris dan Google Scholar untuk mendapat istilah matematika yang sesuai. Kemudian artikel diterjemahkan dengan bantuan Google Translate dan software Gramarly secara online. 
Penulisan Karya Ilmiah Melalui Perkuliahan Seminar Pendidikan Matematika Berbantuan E-Learning dan Media Sosial, Eyus Sudihartinih, Habibi Ratu Perwira Negara, Mimi Nur Hafizah

Pertemuan ke-16 mahasiswa didampingi dosen melakukan pengiriman artikel pada jurnal yang terlebih dahulu mengisi profil di antaranya kode Orchid (diperoleh dengan cara register di https://orcid.org/register) dan dilanjutkan dengan unggah artikel dan file tambahan jika diperlukan. Adapun media sosial aplikasi WhatsApp digunakan agar komunikasi dan informasi dapat cepat sampai pada mahasiswa sehingga pembelajaran berjalan lancar.

Berdasarkan uraian tersebut, proses mahasiswa dalam menulis artikel ilmiah dimulai dengan pertama, mahasiswa menetapkan topik penelitian yang akan dikaji di antaranya proses berpikir, penerapana model pembelajaran, dan lain-lain. Kedua, mahasiswa mengaji topik yang telah di pilih dengan membaca dan menelaah hasil penelitian-penelitian yang telah dilakukan. Proses penelaah berupa: identifikasi hasil temuan, aspek-aspek yang belum dicapai, dan metode penelitian yang digunakan. Ketiga, mahasiswa mencari referensi terkait topik penelitian pada Google Scholar, Researchgate, Eric, dan lain-lain, lalu mengorganirnya dengan menggunakan references manager yaitu Mendeley. Keempat, mahasiswa mempersentasikan artikel yang telah di tulis. Kelima, mahasiswa memperbaiki artikel sesuai masukkan yang diperoleh. Keenam, mahasiswa mengajukan artikel pada salah satu jurnal serta mengikuti proses yang ditetapkan oleh jurnal tersebut, hingga artikel yang diajukan dapat dipublis pada jurnal yang dituju. Tanggapan mahasiswa pada perkuliahan ini ada pada tabel 1. Di mana hasil tersebut diperoleh dengan cara dosen memberikan angket terbuka melalui Google Form.

Tabel 1. Tanggapan Mahasiswa

\begin{tabular}{|c|c|c|c|}
\hline Pertanyaan & Partisipan ke-1 & Partisipan ke-2 & Partisipan ke-3 \\
\hline $\begin{array}{l}\text { Bagaimana cara Anda } \\
\text { tetap semangat belajar } \\
\text { jika sedang sedih, } \\
\text { kecewa, atau bahagia? }\end{array}$ & $\begin{array}{l}\text { Yakin bisa, motivasi } \\
\text { diri, dan tumbuhkan } \\
\text { rasa penasaran untuk } \\
\text { lebih memahami }\end{array}$ & 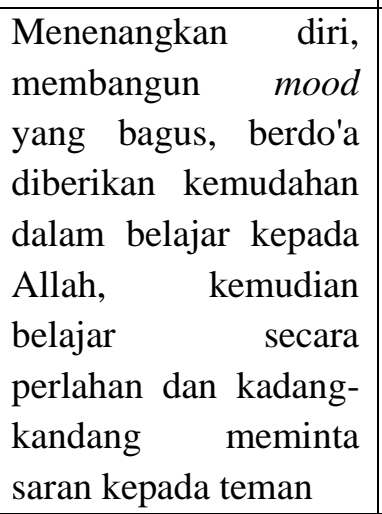 & $\begin{array}{lr}\text { Belajar saya } & \text { tidak } \\
\text { tergantung } & \text { mood } \\
\text { sehingga } & \text { dalam } \\
\text { keadaan } & \text { apapun } \\
\text { insyaAllah dapat terus } & \\
\text { semangat } & \text { dan } \\
\text { konsentrasi } & \text { belajar, } \\
\text { ditunjang } & \text { juga } \\
\text { motivasi yang kuat. }\end{array}$ \\
\hline $\begin{array}{l}\text { Bagaimana } \\
\text { pendapatmu tentang } \\
\text { perkuliahan SPM ini? }\end{array}$ & $\begin{array}{l}\text { Saya sangat terbantu } \\
\text { khususnya dalam } \\
\text { penulisan, waktu, dan } \\
\text { tujuan yang akan } \\
\text { dicapai jelas. On target }\end{array}$ & $\begin{array}{lr}\text { Sangat membantu } \\
\text { untuk menyusun } \\
\text { skripsi nanti }\end{array}$ & $\begin{array}{l}\text { Perkuliahan SPM yang } \\
\text { sekarang ini sangat } \\
\text { membantu saya dalam } \\
\text { memahami bagaimana } \\
\text { cara yang benar dan } \\
\text { mudah dalam menulis } \\
\text { baik itu artikel maupun } \\
\text { makalah, sehingga } \\
\text { saya mendapatkan } \\
\text { gambaran kedepannya } \\
\text { nanti akan seperti apa } \\
\text { untuk skripsi saya. }\end{array}$ \\
\hline
\end{tabular}




\begin{tabular}{|c|c|c|c|}
\hline Pertanyaan & \begin{tabular}{|l} 
Partisipan ke-1 \\
\end{tabular} & Partisipan ke-2 & Partisipan ke-3 \\
\hline $\begin{array}{l}\text { Apa saran Anda } \\
\text { terhadap perkuliahan } \\
\text { ini? }\end{array}$ & \begin{tabular}{|lll} 
Semakin lebih baik \\
lagi
\end{tabular} & $\begin{array}{l}\text { SOP nya ditegaskan } \\
\text { lagi, agar tidak ada } \\
\text { perbedaan antara } \\
\text { mahasiswa yang juga } \\
\text { mengontrak SPM }\end{array}$ & $\begin{array}{lr}\text { Saran saya, kiat-kiat } \\
\text { untuk menulis tetap } \\
\text { dipertahankan dan } \\
\text { diperbanyak lagi }\end{array}$ \\
\hline $\begin{array}{llc}\text { Berikan } & & \text { nilai } \\
\text { pelaksanaan } & & \\
\text { perkuliahan ini } & \text { jika } \\
\text { nilai minimal } 1 & \text { dan } \\
\text { maksimal } & & 10 . \\
\text { Jelaskan! } & & \end{array}$ & $\begin{array}{l}10, \text { karena saya } \\
\text { menyukai adanya } \\
\text { kejelasan bahasan tiap } \\
\text { pertemuan, mengajari } \\
\text { teknik penulisan, dan } \\
\text { selesai tepat pada } \\
\text { waktu yang telah } \\
\text { ditentukan. }\end{array}$ & $\begin{array}{l}\text { 8. Perkuliahan ini } \\
\text { membantu mahasiswa } \\
\text { untuk latihan menulis } \\
\text { skripsi ataupun artikel } \\
\text { yang diharapkan bisa } \\
\text { bermanfaat bagi orang } \\
\text { banyak }\end{array}$ & $\begin{array}{l}\text { 9. Karena saya senang } \\
\text { sekali karena } \\
\text { diperkuliahan ini saya } \\
\text { mendapatkan banyak } \\
\text { ilmu yang bermanfaat }\end{array}$ \\
\hline
\end{tabular}

Berdasarkan tabel 1, proses perkuliahan tentang penulisan karya ilmiah dapat berjalan dengan baik. Selain itu diketahui bahwa semua mahasiswa dapat menyelesaikan artikel dengan baik dan mengirimnya pada jurnal yang terindeks Sinta atau Copernicus. Setelah kurang lebih enam bulan diketahui bahwa artikel telah terbit di jurnal terindeks Sinta dan Copernicus. Sampai dengan tahun 2022, di antaranya terbit di Jurnal Ilmiah Pendidikan Matematika, Edumatika: Jurnal Riset Pendidikan Matematika, Jurnal Pendidikan Matematika, Jurnal Equation Teori dan Penelitian Pendidikan Matematika, PYTHAGORAS: Journal of the Mathematics Education Study Program, Journal of Mathematics Science and Education, dan JP (Jurnal Pendidikan): Teori dan Praktik, dan Mathematics Education Journals (Amaliah \& Sudihartinih, 2019; Azis et al., 2021; Elsa \& Sudihartinih, 2020; Pamungkas \& Sudihartinih, 2021; Pertiwi \& Sudihartinih, 2020; Pratiwi \& Sudihartinih, 2021; Santi \& Sudihartinih, 2019; Trilani \& Sudihartinih, 2022; Umbara \& Sudihartinih, 2020; Wardina \& Sudihartinih, 2019; Wilujeng \& Sudihartinih, 2021).

Publikasi tersebut dilakukan berdasarkan laporan Bashomi bahwa karya ilmiah yang bermutu perlu pembimbingan yang diorientasikan pada publikasi sebagai ukuran keberhasilan yang mudah dilihat karena orientasi karya ilmiah adalah untuk dialog akademik melalui publikasi (Basthomi, 2015). Selain itu, "kemampuan mempublikasikan karya ilmiah di forum internasional meningkatkan kepercayaan masyarakat dunia terhadap mutu produk teknologi suatu bangsa, sehingga devisa yang diraih bangsa tersebut dipasaran global juga meningkat" seperti yang disampaikan oleh Direktorat Penelitian dan Pengabdian Kepada Masyarakat Dirjen Dikti (Rohmah et al., 2016).

Penulis tidak menemukan adanya kendala pada penelitian ini, berbeda dengan temuan peneliti lain yang menghadapi kendala. Kendala dalam membuat karya ilmiah adalah rendahnya minat membaca dan menulis, keterbatasan bahan bacaan, kurangnya pengalaman untuk menulis, kurangnya pemahaman agar terampil menulis, dan rendahnya motivasi untuk menulis (Permana \& Dkk, 2017). Beberapa penyebab rendahnya motivasi menulis karya ilmiah adalah ketakutan atau kecemasan menulis terkait dengan prosedur dan kriteria tulisan yang dapat diterima dan dihargai sebagai karya 
Penulisan Karya Ilmiah Melalui Perkuliahan Seminar Pendidikan Matematika Berbantuan E-Learning dan Media Sosial, Eyus Sudihartinih, Habibi Ratu Perwira Negara, Mimi Nur Hafizah

ilmiah (Jaedun, 2011). Selanjutnya dosen memberikan pertanyaan lanjutan melalui aplikasi WhatsApp. Adapun pertanyaan dan respons tersebut terdapat pada Tabel 2.

Tabel 2. Tanggapan Mahasiswa terhadap E- Learning dan Media Sosial

\begin{tabular}{|c|c|c|c|}
\hline Pertanyaan & Partisipan ke-1 & Partisipan ke-2 & Partisipan ke-3 \\
\hline $\begin{array}{l}\text { Apakah SPADA } \\
\text { membantu kuliah } \\
\text { SPM? }\end{array}$ & $\begin{array}{l}\text { Sangat membantu, } \\
\text { khususnya dalam } \\
\text { pengumpulan tugas dan } \\
\text { revisi, sangat paperless, } \\
\text { dan bisa memuat banyak } \\
\text { konten untuk materi } \\
\text { terkait }\end{array}$ & $\mathrm{Ya}$ & $\begin{array}{l}\text { Membantu untuk lebih } \\
\text { mudah ketika akan } \\
\text { bimbingan, tidak perlu } \\
\text { untuk print dulu, dan } \\
\text { hemat kertas }\end{array}$ \\
\hline $\begin{array}{l}\text { Apakah grup WA } \\
\text { membantu kuliah } \\
\text { SPM? }\end{array}$ & $\mathrm{Ya}$ & $\mathrm{Ya}$ & $\begin{array}{l}\text { Sangat membantu dalam } \\
\text { memberikan info-info } \\
\text { yang bermanfaat dan } \\
\text { dapat mempermudah } \\
\text { komunikasi }\end{array}$ \\
\hline $\begin{array}{l}\text { Berilah nilai } 1-10 \\
\text { untuk } \\
\text { kebermanfaatan } \\
\text { SPADA di kuliah } \\
\text { SPM. }\end{array}$ & 8 & 8 & 9 \\
\hline $\begin{array}{l}\text { Berilah nilai } 1-10 \\
\text { untuk } \\
\text { kebermanfaatan } \\
\text { grup WA di kuliah } \\
\text { SPM. }\end{array}$ & 8 & 8 & 10 \\
\hline $\begin{array}{l}\text { Apa saran pada } \\
\text { konten SPADA? }\end{array}$ & $\begin{array}{l}\text { Lebih ditingkatkan } \\
\text { fiturnya. Seperti banyak } \\
\text { bisa memuat yang lain } \\
\text { juga Bu, kan selama ini } \\
\text { kita taunya buat upload } \\
\text { sesuatu aja ya Bu. Tapi } \\
\text { udah cukup baik Bu } \\
\text { sudah lengkap Bu. }\end{array}$ & $\begin{array}{l}\text { Ada } \\
\text { reminder/pengingat } \\
\text { yang terhubung ke } \\
\text { email mahasiswa agar } \\
\text { tidak melewati batas } \\
\text { submit tugas }\end{array}$ & $\begin{array}{l}\text { Sudah bagus, perbanyak } \\
\text { video kuliah umum }\end{array}$ \\
\hline $\begin{array}{l}\text { Apa saran pada } \\
\text { konten WA? }\end{array}$ & $\begin{array}{l}\text { Lebih banyak memuat } \\
\text { bahasan lagi. Tapi } \\
\text { keseluruhan sudah baik } \\
\text { Bu menurut saya mah. }\end{array}$ & Sudah cukup & Sudah bagus \\
\hline
\end{tabular}

Berdasarkan Tabel 2 diketahui bahwa semua mahasiswa memiliki respons yang baik terhadap perkuliahan. Hasil penelitian sebelumnya juga menunjukkan bahwa sebagian mahasiswa merasa tertarik untuk mengikuti $e$-learning karena untuk meningkatkan kemampuan dalam bidang teknologi (Mardhiyana \& Nasution, 2018). 
Temuan penelitian ini juga sejalan dengan laporan sebelumnya. Melalui $e$-learning, dosen dapat mengunggah materi sebelum perkuliahan sehingga mahasiswa dapat mempelajari materi tersebut, membuat lebih mudah mengerti saat perkuliahan, terbukti mahasiswa mampu menyelesaikan soal-soal dengan baik (Hadi \& Rulviana, 2018). Desain perangkat pembelajaran menggunakan media $e$ learning memberikan kesempatan kepada mahasiswa untuk berpikir terbuka dan dapat melakukan komunikasi tanpa harus tatap muka, serta dapat segera mengirimkan tugas-tugasnya (Handayanto et al., 2015). Pada penelitian ini tidak dilakukan full e-learning sehingga penulisan karya ilmiah berhasil. Sesuai dengan laporan sebelumnya bahwa daya matematika mahasiswa yang pembelajarannya melalui blended learning lebih baik dibandingkan melalui full e-learning dan konvensional (Yaniawati, 2012). Berdasarkan temuan penelitian juga diketahui bahwa partisipan memberikan saran perlunya penambahan konten e-learning. Oleh karena itu, perlunya dilakukan penelitian lebih lanjut. Selain itu perlunya pengembangan pembelajaran e-learning yang tepat sesuai dengan kebutuhan (Yazdi, 2012).

\section{KESIMPULAN}

Mahasiswa harus memiliki kemampuan menulis karya ilmiah karena merupakan kompetensi yang harus dimiliki. Penulisan karya ilmiah di antaranya dapat dilakukan dalam perkuliahan Seminar Pendidikan Matematika berbantuan e-learning dan media sosial. Berdasarkan hasil penelitian diketahui bahwa pendampingan penulisan karya ilmiah dilakukan dengan baik oleh semua mahasiswa. Selain itu, mahasiswa juga memberikan respons yang positif terhadap perkuliahan sehingga perkuliahan yang berbantuan e-learning dan media sosial dapat dilanjutkan dalam perkuliahan berikutnya dan diujikan pada penelitian lainnya.

\section{UCAPAN TERIMA KASIH}

Penulis mengucapkan terima kasih yang sebesar-besarnya pada seluruh partisipan dan Kemendikbud Ristek Dikti Program Revitalisasi LPTK yang telah mendanai penelitian ini sehingga penelitian selesai dengan baik.

\section{REFERENSI}

Amaliah, I., \& Sudihartinih, E. (2019). Pengembangan Bahan Ajar Konsep Pecahan Berbantuan Multimedia Untuk Meningkatkan Kemampuan Pemahaman Matematis Siswa Di Sekolah Inklusi. Jurnal Pendidikan, 4(2), 6-10.

Assidik, G. K. (2018). Pemanfaatan media sosial sebagai alternatif media pembelajaran berbasis literasi digital yang interaktif dan kekinian. Prosiding SAGA, 242-246.

Azis, B. A., Sudihartinih, E., Matematika, S. P., Indonesia, U. P., Studi, P., Matematika, P., \& Indonesia, U. P. (2021). Kemampuan Komunikasi Matematis Siswa Kelas Viii Mts Negeri 2. 4, 91-102.

Basthomi, Y. (2015). Mentoring penulisan karya ilmiah. Jurnal Ilmu Pendidikan, 21(1), 115-125. 
Penulisan Karya Ilmiah Melalui Perkuliahan Seminar Pendidikan Matematika Berbantuan E-Learning dan Media Sosial, Eyus Sudihartinih, Habibi Ratu Perwira Negara, Mimi Nur Hafizah

Bielawski, L., \& Metcalf, D. (2003). Blended eLearning.

Clark, R. C., \& Mayer, R. E. (2008). E-learning and the science of instruction (second edition).

Ehlers, U.-D., \& Pawlowski, J. M. (2006). Handbook on quality and standardisation in e-learning.

Elsa, Ih. A., \& Sudihartinih, E. (2020). Error Analysis of High School Students on Linear Program Topics Based on Newman Error Analysis Hanne Ayuningtias Elsa, Eyus Sudihartinih. Mathematics Education Journals, 4(1), 7-16.

Hadi, F. R., \& Rulviana, V. (2018). Analisis Proses Pembelajaran E-Learning Berbasis Edmodo pada Mata Kuliah Geometri. Jurnal Bidang Pendidikan Dasar, 2(1), 63-68.

Handayanto, A., Supandi, R., \& Ariyanto, L. (2015). Pembelajaran E-Learning menggunakan Moodle pada matakuliah Metode Numerik. Jurnal Informatika UPGRIS, 1, 42-48.

Hanum, F. (2009). Strategi Penulisan Karya Ilmiah. Makalah Pada Diseminasi Penyususnan Karya Ilmiah Yang Diselengarakan Oleh Badan Kepegawaian Pemerintah Yogyakarta.

Jaedun, A. (2011). Pengembangan Profesionalisme Guru Melalui Penulisan Karya Tulis Ilmiah. Makalah Disampaikan Pada Kegiatan Seminar Karya Tulis Ilmiah Dan Penelitian Tindakan Kelas Di SMK Negeri 1 Sedayu, Bantul, 0-14.

Kurniadi, F. (2017). Penulisan Karya Tulis Ilmiah Mahasiswa Dengan Media Aplikasi Pengolah Kata. AKSIS: Jurnal Pendidikan Bahasa Dan Sastra Indonesia, 1, 267-277.

Mardhiyana, D., \& Nasution, N. B. (2018). Kesiapan Mahasiswa Pendidikan Matematika Menggunakan E-Learning dalam Menghadapi Era Revolusi Industri 4 . 0. Seminar Nasional Pendidikan Matematika Ahmad Dahlan, 31-35.

Nasution, M. K. M. (2016). Carut Marut Menulis Karya Ilmiah. Harian Waspada, Opini, B7.

Pamungkas, D., \& Sudihartinih, E. (2021). Analisis Kebutuhan Mahasiswa Calon Guru Matematika Terhadap Aplikasi GeoGebra Pada Pembelajaran Geometri Analitik. Jurnal Pendidikan Matematika, 9(2), 223-232.

Peraturan Rektor UPI. (2018). Pedoman Penulisan Karya Ilmiah UPI (UPI).

Permana, E. P., \& Dkk. (2017). Pelatihan Penulisan Karya Ilmiah Untuk Guru Sekolah Dasar Pada Anggota Gugus 1 Kecamatan Ringinrejo. ABDINUS Jurnal, 1(1).

Pertiwi, M., \& Sudihartinih, E. (2020). Analisis kemampuan berpikir geometri van hiele siswa sekolah menengah pertama ditinjau dari perspektif gender. PYTHAGORAS: Jurnal Program Studi Pendidikan Matematika, 9(2), 86-94.

Pratiwi, I. S., \& Sudihartinih, E. (2021). Analysis of Junior High School Students' Mathematical Connection on The Ratio and Proportion Concepts. Edumatika: Jurnal Riset Pendidikan Matematika, 4(1), 59-76. https://doi.org/10.32939/ejrpm.v4i1.753

Rohmah, N., Muhammad, A. H. Y., \& Kusmintardjo. (2016). Strategi Peningkatan Kemampuan Dosen Dalam Penulisan Karya Ilmiah ( Studi Multi Kasus Pada Unisda Dan Staidra. Jurnal Pendidikan: Teori, Penelitian, Dan Pengembangan, 1(7), 1312-1322.

Santi, L. M., \& Sudihartinih, E. (2019). Analisis kesalahan siswa sekolah menengah pertama pada materi pecahan. 04, 1-5.

Saputra, J., \& Pasundan, U. (2017). Model Problem Based Learning Berbantuan E - Learning Terhadap Kemandirian Belajar Mahasiswa. Kalamatika Jurnal Pendidikan Matematika, 2(2), 
$117-130$.

Trilani, S. S., \& Sudihartinih, E. (2022). Analisis Kebutuhan Video pada Pembelajaran Matematika Mahasiswa Calon Guru di Masa Pandemi Covid-19. Jurnal Ilmiah Pendidikan Matematika, $10(2), 317-330$.

Umbara, F. D. A. D., \& Sudihartinih, E. (2020). HASIL BELAJAR DAN EFIKASI DIRI SISWA SEKOLAH MENENGAH PERTAMA PADA MATA PELAJARAN MATEMATIKA. SIGMA, 6(1), 8-16.

Wardina, A. S., \& Sudihartinih, E. (2019). DESCRIPTION OF STUDENT' S JUNIOR HIGH SCHOOL MATHEMATICAL CONNECTION ABILITY ON THE LINEAR FUNCTION TOPIC Penerbit : LP4MK STKIP PGRI Lubuklinggau. 2(1), 24-35.

Wilujeng, S., \& Sudihartinih, E. (2021). Kemampuan Berpikir Kritis Matematis Siswa SMP Ditinjau dari Gaya Belajar Siswa. JPMI (Jurnal ..., September, 53-63.

Yaniawati, R. P. (2012). Pengaruh E-Learning Untuk Meningkatkan Daya Matematik Mahasiswa. Cakrawala Pendidikan, XXXI(3), 381-393.

Yazdi, M. (2012). E-Learning Sebagai Media Pembelajaran. Jurnal Ilmiah Foristek, 2(1), 143-152.

Yin, R. K. (2009). Case study research: Design and methods (4th Ed.). SAGE. 